\title{
A Case of Inflammatory Hepatocellular Adenoma Complicated by Steatohepatitis
}

\author{
Yohei Harima1 $^{*}$, Naoki Urayama ${ }^{1}$, Fusako Hisano1, Yuko Matsuzaki ${ }^{1}$, Kazutoshi Sanuki' \\ Taichi Kuwahara², Tadashi Kaneko², Toshio Harada², Toru Kawaoka², Sakurao Hiraki², \\ Shintaro Fukuda², Kiwamu Okita3 ${ }^{3}$, Osamu Nakashima ${ }^{4}$ \\ ${ }^{1}$ Department of Gastroenterological Medicine, Ube Industries Central Hospital, Ube, Japan \\ ${ }^{2}$ Department of Surgery, Ube Industries Central Hospital, Ube, Japan \\ ${ }^{3}$ Department of Gastroenterology and Hepatology, Social Insurance Shimonoseki Kohsei Hospital, Shimonoseki, \\ Japan \\ ${ }^{4}$ Department of Clinical Laboratory Medicine, Kurume University Hospital, Kurume, Japan \\ Email: ${ }^{*}$ harima980732@gmail.com
}

Received 29 January 2014; revised 2 March 2014; accepted 10 March 2014

Copyright (C) 2014 by authors and Scientific Research Publishing Inc.

This work is licensed under the Creative Commons Attribution International License (CC BY). http://creativecommons.org/licenses/by/4.0/

(c) (i) Open Access

\section{Abstract}

A 54-year-old man with hypertension, dyslipidemia, diabetes mellitus and fatty liver was referred to our institution for accurate diagnosis of a 4-cm space-occupying lesion in subsegment 6 of the liver, identified on ultrasonography as an iso-to hypointense lesion with clear margins. Dynamic computed tomography disclosed light accumulation of contrast medium at the margins of the space-occupying lesion from the arterial phase through to the venous phase. Sonazoid-enhanced ultrasonography showed staining of the tumor margins in the vascular phase, disappearing in the post-vascular phase. Hepatic arteriography identified the space-occupying lesion as hypervascular. Since accurate diagnosis by imaging was difficult, tumor resection was performed to exclude hepatocellular carcinoma, after obtaining consent from the patient. Histological examination revealed steatohepatitis and sinusoidal dilatation, representing so-called peliosis hepatis, in the surroundings, while the tumor showed mild hepatocellular atypia. On immunohistochemistry, tumor cells were positive for liver fatty acid-binding protein, glutamine synthetase and serum amyloid $A$, and negative for $\beta$-catenin and glypican 3. Glutamine synthetase, in particular, showed strong diffuse staining. Inflammatory hepatocellular adenoma was thus considered the most likely diagnosis. The pathogenesis and outcome of inflammatory hepatocellular adenoma are not fully understood, and this case with concomitant steatohepatitis was considered worth reporting.

\section{Keywords}

Inflammatory Hepatocellular Adenoma (IHCA); Steatohepatitis; Non-Alcoholic Fatty Liver Disease

\footnotetext{
${ }^{*}$ Corresponding author.
} 


\section{Introduction}

Development of hepatocellular carcinoma (HCC) has been noted among patients with either chronic viral hepatitis after infection with hepatitis $\mathrm{B}$ or $\mathrm{C}$ virus or non-alcoholic fatty liver disease (NAFLD). However, the process of hepatocarcinogenesis with NAFLD is unclear. Hepatocellular adenoma (HCA), which is often induced by long-term oral contraceptive usage, also sometimes progresses to cancer [1]-[7]. Recently, HCA has been classified into the following subgroups based on genotype and phenotype: 1) hepatocyte nuclear factor (HNF) $1 \alpha$ inactivated type; 2) $\beta$-catenin activated type; 3) inflammatory hepatocellular adenoma (IHCA) and 4) unclassified type [2] [3]. Determining the presence or absence of liver fatty acid-binding protein (LFABP), glutamine synthetase (GS) and serum amyloid A (SAA) is essential for subgrouping of HCA. Among HCAs, IHCA develops in liver injured by inflammatory liver disease including steatohepatitis [2] [3] [8]. Although NAFLD is known to be associated with a higher risk of HCC development [9]-[15], evidence of how such HCC arises remains lacking. In this case, we tried to clarify the characteristics of a space-occupying lesion (SOL) identified against a background of NAFLD from the perspective of phenotype.

\section{Case Report}

A 54-year-old man with no history of alcohol intake or cigarette smoking was being followed up by his local physician for hypertension, dyslipidemia, diabetes mellitus and fatty liver. He had been treated with olmesartan, amlodipine, glimepride, femofibrate and voglibose. A recent ultrasonography (US) had disclosed the presence of a SOL $4 \mathrm{~cm}$ in diameter in the liver, and he was referred to our hospital for further examination of this lesion. On presentation, body mass index (BMI) was $31.2 \mathrm{~kg} / \mathrm{m}^{2}$ and blood pressure was 162/83 mmHg. Laboratory data indicated slight dyslipidemia. Hemoglobin A1c level was 6.3\%. Results from liver function testing were within normal limits. Levels of tumor markers, such as $\alpha$-fetoprotein and des- $\gamma$-carboxyprothrombin, also known as protein induced by vitamin $\mathrm{K}$ absence/antagonist-II (PIVKA-II), were within normal limits. Negative results were obtained for hepatitis B surface antigen and hepatitis $C$ virus antibody (Table 1). Physical examination did not reveal the presence of any abnormalities, including hepatosplenomegaly.

Table 1. Laboratory data on admission.

\begin{tabular}{|c|c|c|c|c|c|}
\hline \multicolumn{2}{|c|}{ Hematology } & \multirow[b]{2}{*}{ BUN } & \multirow[b]{2}{*}{23 mg/dl } & \multicolumn{2}{|c|}{ Serology } \\
\hline WBC & $9110 / \mu 1$ & & & ANA & 40 \\
\hline RBC & $542 / \mu 1$ & Cre & $1.50 \mathrm{mg} / \mathrm{dl}$ & AMA(M2) & $<5$ \\
\hline $\mathrm{Hb}$ & $15.5 \mathrm{~g} / \mathrm{dl}$ & LDH & 246 IU/l & IgG & $941 \mathrm{mg} / \mathrm{dl}$ \\
\hline $\mathrm{Ht}$ & $46.3 \%$ & UA & $5.4 \mathrm{mg} / \mathrm{dl}$ & $\operatorname{IgM}$ & 67 mg/dl \\
\hline Plt & $23.3 / \mu 1$ & $\mathrm{Na}$ & $146 \mathrm{mEq} / \mathrm{l}$ & IgA & $261 \mathrm{mg} / \mathrm{dl}$ \\
\hline \multicolumn{2}{|c|}{ Biochemistry } & $\mathrm{K}$ & $5.0 \mathrm{mEq} / \mathrm{l}$ & HBsAg & $(-)$ \\
\hline TP & $7.6 \mathrm{~g} / \mathrm{dl}$ & $\mathrm{Cl}$ & 108 mEq/l & HCVAb & $(-)$ \\
\hline Alb & $4.7 \mathrm{~g} / \mathrm{dl}$ & T-Cho & 218 mg/dl & \multicolumn{2}{|c|}{ Tumor markers } \\
\hline TB & $0.5 \mathrm{mg} / \mathrm{dl}$ & LDL & 153 mg/dl & AFP & $2.4 \mathrm{ng} / \mathrm{ml}$ \\
\hline FBS & $129 \mathrm{mg} / \mathrm{dl}$ & HDL & 37 mg/dl & PIVKA-2 & $36 \mathrm{mAU} / \mathrm{ml}$ \\
\hline CRP & $1.7 \mathrm{mg} / \mathrm{dl}$ & TG & 195 mg/dl & CEA & $2.7 \mathrm{ng} / \mathrm{ml}$ \\
\hline AST & $12 \mathrm{IU} / \mathrm{l}$ & $\mathrm{Fe}$ & $74 \mu \mathrm{g} / \mathrm{dl}$ & CA19-9 & $11 \mathrm{U} / \mathrm{ml}$ \\
\hline ALT & $16 \mathrm{IU} / \mathrm{l}$ & Ferritin & 230 ng/ml & DUPAN-2 & $25 \mathrm{U} / \mathrm{ml}$ \\
\hline ALP & $160 \mathrm{IU} / \mathrm{l}$ & $\mathrm{Cu}$ & $92 \mu \mathrm{g} / \mathrm{dl}$ & Span-1 & $13 \mathrm{U} / \mathrm{ml}$ \\
\hline$\gamma$-GTP & $30 \mathrm{IU} / \mathrm{l}$ & Ceruloplasmin & $24 \mathrm{mg} / \mathrm{dl}$ & IL2-R & $468 \mathrm{U} / \mathrm{ml}$ \\
\hline ChE & $403 \mathrm{mg} / \mathrm{dl}$ & IRI & 25 mmU/l & & \\
\hline
\end{tabular}


For accurate diagnosis of the SOL, the following imaging techniques were applied. Magnetic resonance imaging was not performed due to the patient feeling claustrophobic.

\subsection{Ultrasonography (US) (Figure 1)}

The SOL was $41 \times 38 \mathrm{~mm}$ in size and clearly demarcated from the surrounding tissue, in subsegment 6 of the right hepatic lobe. The lesion showed a mosaic pattern of iso-to hypointensity. Blood flow was identified on color Doppler US. In the background liver, US showed severe fatty liver.

\subsection{Sonazoid-Enhanced US (Figure 2)}

The margins of the SOL were stained in the vascular phase, although this staining disappeared rapidly. The SOL was thus assessed as being defective in the post-vascular phase.

\subsection{Dynamic Computed Tomography (CT) (Figure 3)}

Plain CT indicated a low-density SOL in subsegment 6 of the liver. In the early phase, soon after injection of the contrast medium, the SOL showed staining of the margins. This staining was maintained even in the late phase. The center of the SOL remained unstained.

\subsection{Hepatic Angiography (Figures 4(a) and (b))}

Hepatic arteriography showed the accumulation of contrast medium in the SOL. No marked irregularity of the vessels was apparent.

\subsection{CTAP/CTHA (Figure 5)}

CT during arterial portography (CTAP) showed iso-density with the SOL in segment 6. CT during hepatic arteriography (CTHA) showed staining of the margins of the SOL from the early phase maintained into the late phase.

\subsection{FDG-PET/CT (Figure 6)}

Accumulation of FDG was observed in the SOL, but at low intensity (maximum standardized uptake value, 1.69).

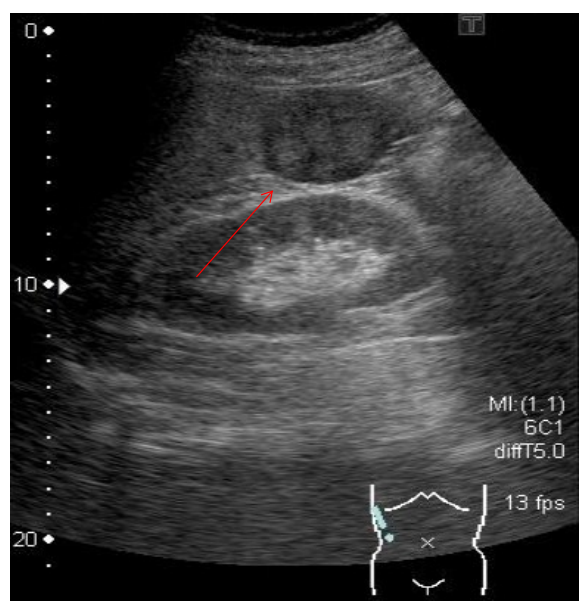

Figure 1. On ultrasonography (US), the SOL (arrow) was $41 \times 38 \mathrm{~mm}$ in size and clearly demarcated from the surrounding tissue, in subsegment 6 of the right hepatic lobe. The lesion (arrow) showed a mosaic pattern of iso-to hypodensity. Blood flow was identified on color Doppler US. 
Vascular phase

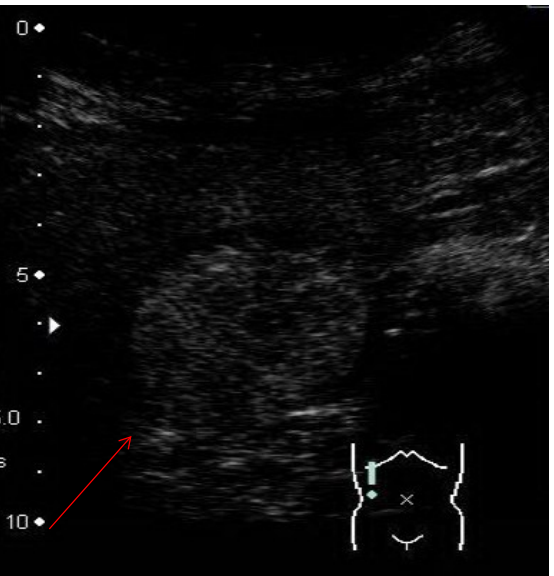

Post-vascular phase

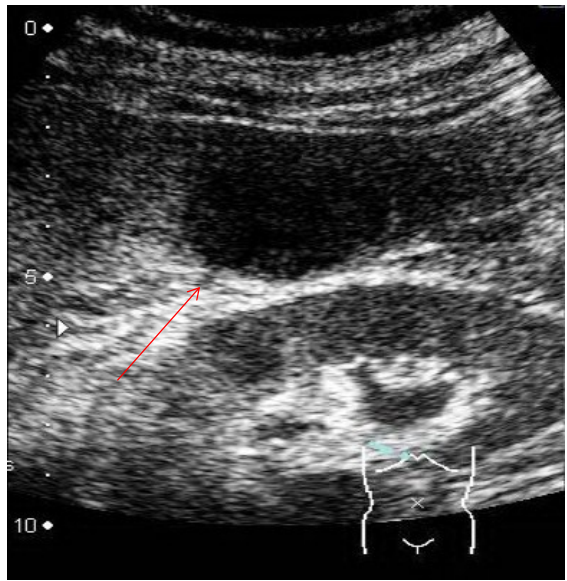

Figure 2. Sonazoid-enhanced US. The margins of the SOL (arrow) stained in the vascular phase, although staining disappeared rapidly. The SOL (arrow) was deemed to be defective in the post-vascular phase.

Early phase

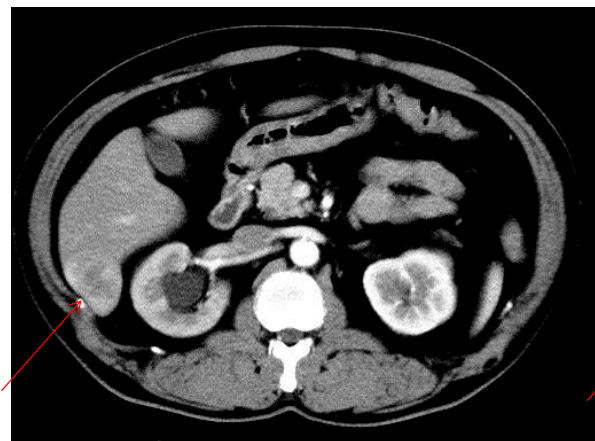

Late phase

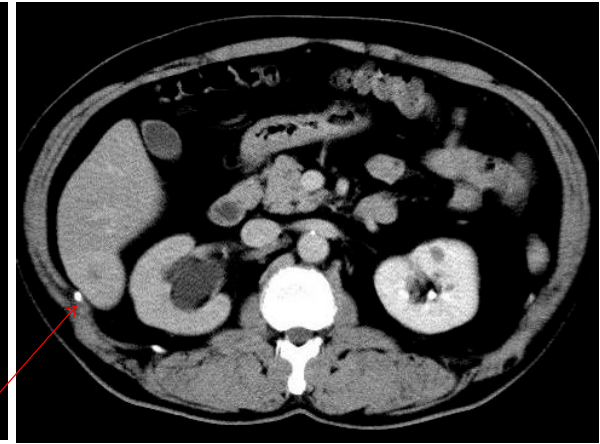

Figure 3. Dynamic computed tomography (CT). The SOL (arrow) showed staining of the margins from the early phase maintained through to the late phase. The center of the SOL remained unstained.

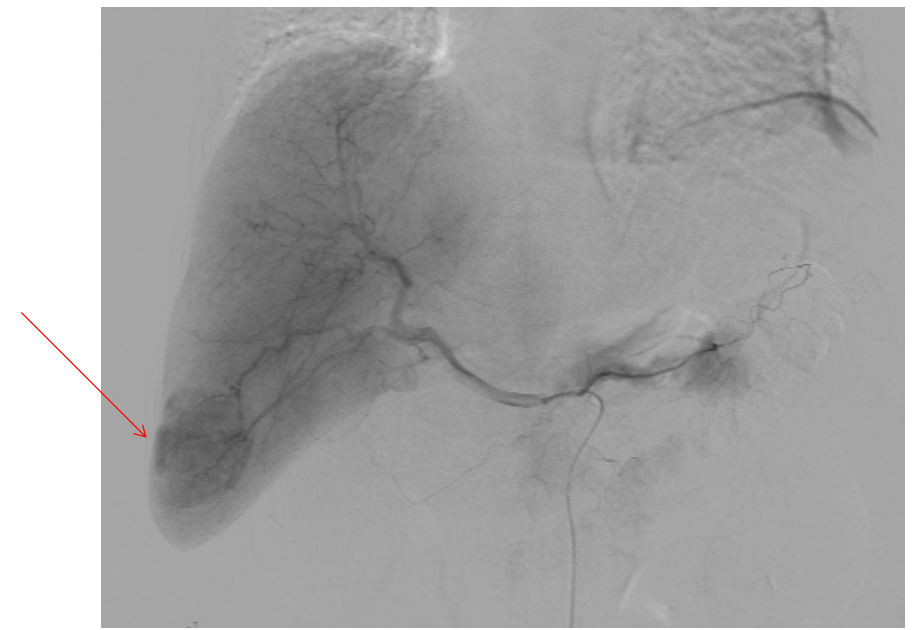

Figure 4. Hepatic angiography demonstrated accumulation of contrast medium in the SOL (arrow). No marked irregularity of vessels was apparent. 


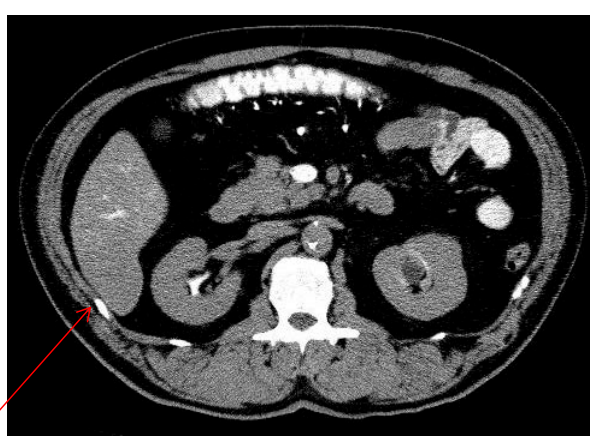

CTAP

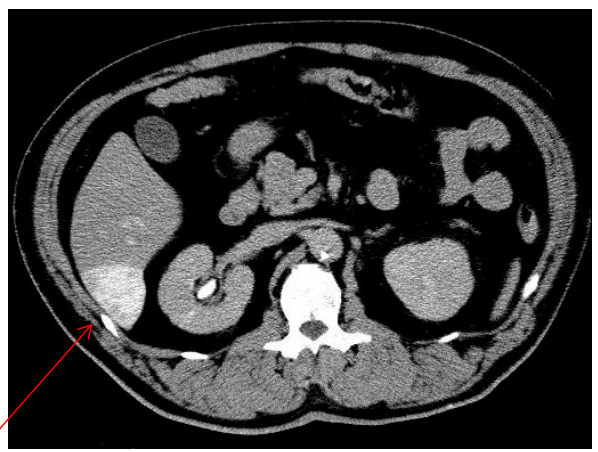

CTHA (middle)

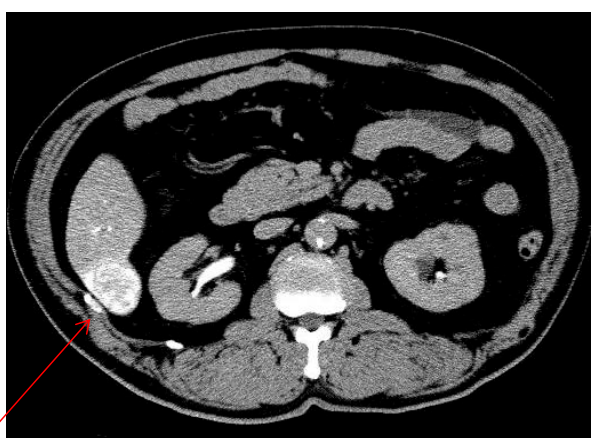

CTHA (early)

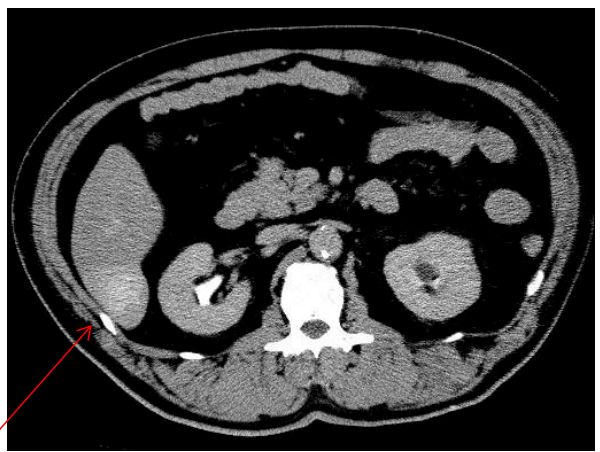

CTHA (delayed)

Figure 5. CT during arterial portography (CTAP) showed iso-density with the SOL (arrow) in segment 6. CT during hepatic arteriography (CTHA) showed staining of the margins of the SOL (arrow) from the early phase maintained into the late phase.

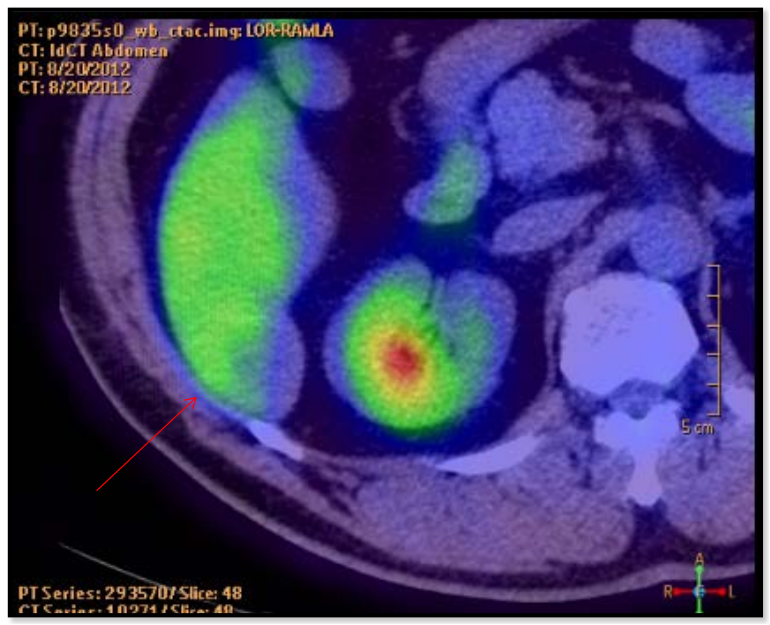

Figure 6. Fluorodeoxyglucose-positron emission tomography (FDG-PET) demonstrated accumulation of FDG in the SOL (arrow), but at low intensity (maximum standardized uptake value, 1.69).

Since accurate diagnosis based on the results of imaging was difficult, tumor resection was recommended for histological confirmation of HCC. Resection was therefore performed after obtaining consent from the patient.

\subsection{Resected Tumor (Figures 7(a)-(f))}

The removed tumor was soft and solid, accompanied by hemorrhage. The tumor was not encapsulated by fibr- 


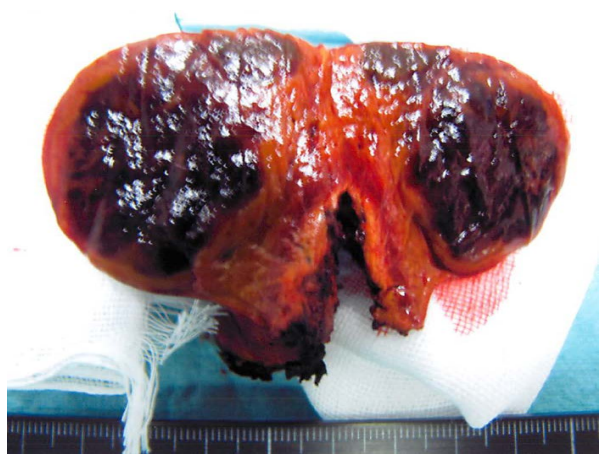

(a)

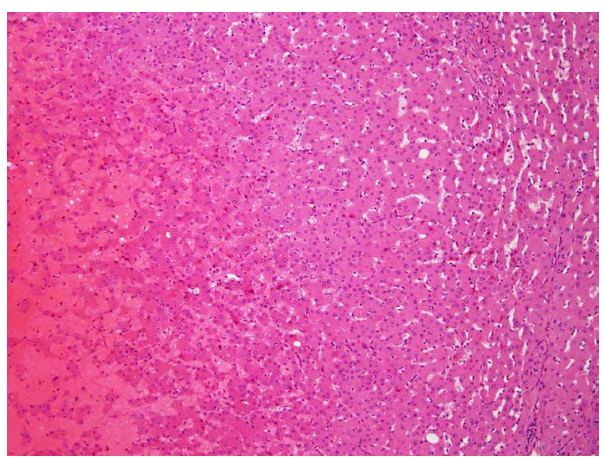

(c)

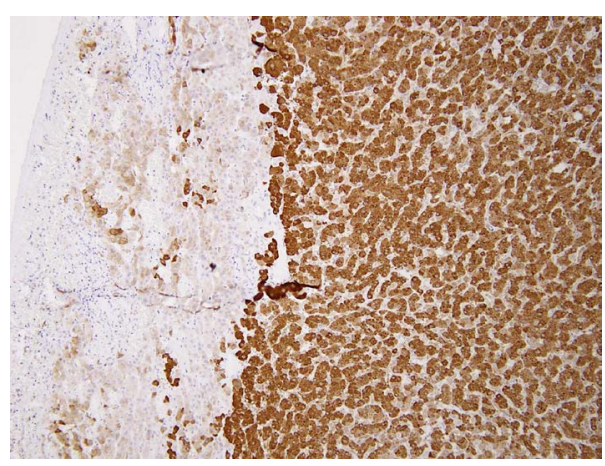

40×, Glutamine synthetase (GS)

(e)

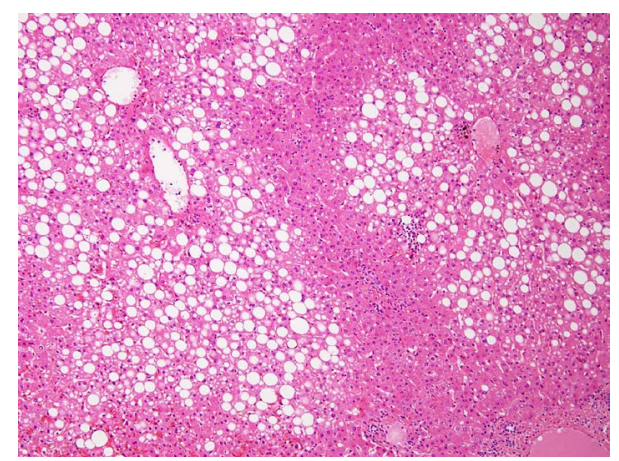

(b)

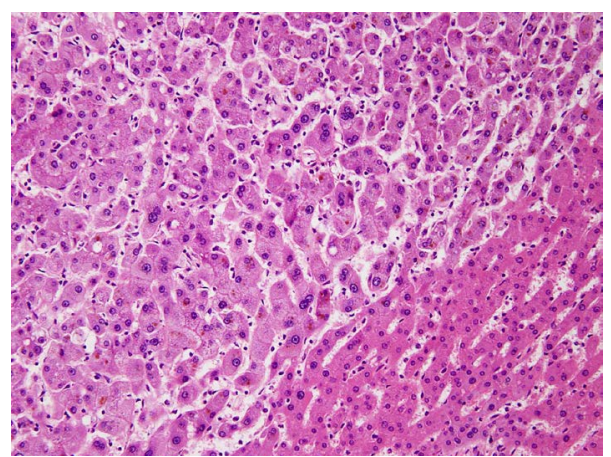

(d)

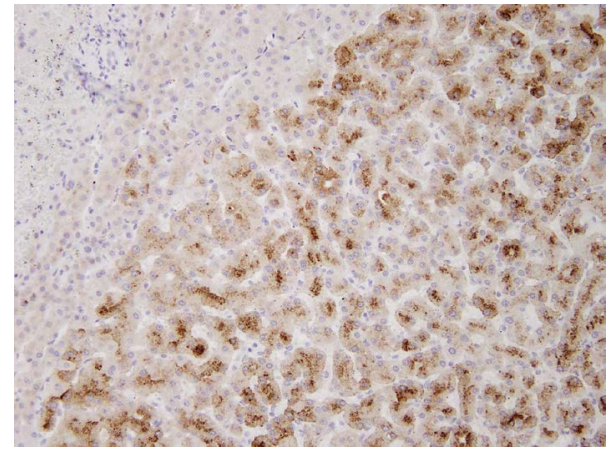

100×, Serum amyloid A (SAA)

(f)

Figure 7. (a) The removed tumor was soft and solid, accompanied by hemorrhage. The tumor was not encapsulated in fibrous tissue; (b) Microscopic examination of the resected liver. Fat deposits and lymphocytic infiltration were seen in the resected liver specimen. However, no ballooning degeneration or Mallory-Denk bodies, indicative of NASH, were seen, 40x; (c) $40 \times$ and (d) $100 \times$ Histological examination revealed that the tumor consisted of hepatocytes with low-grade dysplasia in a trabecular arrangement. However, no mitosis or increased nucleus/cytoplasm ratio, which would have been indicative of HCC, was observed, while marked peliosis hepatis was apparent; (e) 40×; Glutamine synthetase (GS) and, (f) 100×; Serum amyloid A (SAA) Immunohistochemical studies for liver fatty acid-binding protein (LFABP), glutamine synthetase (GS), $\beta$-catenin, serum amyloid A (SAA) and glypican 3 were performed to clarify tumor characteristics. Tumor cells were found to be negative for $\beta$-catenin in the nucleus and for glypican 3 , but positive for LFABP, GS and SAA. The histological findings and localization of SAA suggested inflammatory hepatocellular adenoma (IHCA) as the appropriate histological diagnosis.

ous tissue. Histological examination revealed that the tumor consisted of hepatocytes showing low-grade dysplasia in a trabecular arrangement. However, no mitosis or increased nucleus/cytoplasm ratio, indicative of HCC, was observed, and marked peliosis hepatis was apparent. Fat deposits and lymphocytic infiltration were seen in 
the background liver. However, no ballooning degeneration or Mallory-Denk bodies indicative of NASH were apparent in the background liver.

Immunohistochemical studies for LFABP, GS, $\beta$-catenin, SAA and glypican 3 were performed to clarify tumor characteristics. Tumor cells were found to be negative for $\beta$-catenin in the nucleus and for glypican 3 , but positive for LFABP, GS and SAA. In particular, strong diffuse staining was seen for GS (immunohistochemistry was performed at Kurume University Hospital). Taken together, the histological findings and localization of SAA suggested IHCA as the most probable histological diagnosis.

\section{Discussion}

HCA is a benign tumor caused by the local growth of hepatocytes, and is often seen in young women on oral contraceptives [1]-[3]. According to recent reports from Europe, more than 90\% of patients with HCA are women using oral contraception [3] [11]. In Japan, the frequency of HCA in women is not particularly high, presumably due to the limited use of oral contraceptives [6]. Despite the benign nature of the condition, a potential for malignant transformation of HCA has been suggested. For such malignant change, $\beta$-catenin mutation is of major interest and more aggressive management in cases showing such mutation may be needed due to the high risk of HCC developing [2]-[4]. In addition, Farges et al. examined cases over the last 15 years and reported that risk of HCC development among HCA is 10 times higher in men than in women [4]. In China, Lin et al. reported that HCA accompanied by persistent HBV infection and tumor more than $10 \mathrm{~cm}$ in diameter indicates an increased risk of HCC development [7].

According to the World Health Organization classification of diseases of the digestive system [2], HCA can be classified into four types according to phenotype [2] [3] [16]-[18]. The first is HNF $1 \alpha$ inactivated type (35\% - 40\%), which displays characteristic pathological features including marked steatosis or adenomatosis. The absence of LFABP expression is diagnostic for this subgroup. The second type is $\beta$-catenin activated type (10\% $15 \%)$, which is characterized by overexpression of GS and aberrant nuclear $\beta$-catenin staining. These lesions characteristically arise in men and are associated with a higher risk of HCC. The third type is IHCA (45\% $60 \%$ ), defined by the presence of inflammatory cell infiltration, sinusoidal dilatation and thick-walled arteries. There is an overexpression of the inflammatory proteins SAA and C-reactive protein in tumor hepatocytes at both the mRNA and protein levels. The final type is unclassified type (5\% - 10\%), showing HCA without HNF $1 \alpha$ or $\beta$-catenin gene mutation and inflammatory protein expression. In the present case, localizations of L-FABP, GS, SAA, $\beta$-catenin and glypican 3 were studied immunohistochemically. The resected tumor was found to be positive for L-FABP, GS and SAA, but negative for $\beta$-catenin and glypican 3 . Histological examination revealed fatty liver accompanied by inflammatory cell infiltration and sinusoidal dilatation, as so-called peliosis hepatis, in the surrounding tissue, while the tumor showed mild hepatocellular atypia. Together, the histological and immunohistochemical findings indicated IHCA as the appropriate pathological diagnosis. IHCA is the most common subtype and accounts for about $45 \%-60 \%$ of all HCAs. IHCA occurs most frequently in young women with a history of using contraceptive pills, as for HCA, and in obese patients. In addition, Sasaki et al. reported that IHCA was founded in patients with alcoholic cirrhosis [5]. However, the outcomes of IHCA are not fully understood. The present case revealed strong diffuse staining for GS. According to Bioulac-Sage et al., strong diffuse staining for GS provides convincing evidence of $\beta$-catenin mutation, which in turn may indicate an increased risk of HCC development [3]. $\beta$-catenin mutations are found in $20 \%-34 \%$ of HCC, suggesting that $\beta$-catenin is one of the most frequently activated oncogenes in HCC [19]-[21].

HCA is difficult to characterize on imaging, and can be difficult to differentiate from well-differentiated HCC, or sometimes from regenerative lesions such as focal nodular hyperplasia. Angiographic features of HCA include staining in the early phase that is maintained into the late phase [22] [23]. In the present case, staining of the lesion margins was maintained into the late phase, but the center was not stained due to internal hemorrhage. Magnetic resonance imaging (MRI) is considered the most informative imaging modality for classifying HCA, because findings such as fat, sinusoidal dilatation and necrotic or hemorrhagic components can be identified [24]. Katabathina et al. reported that IHCA, accompanied by marked sinusoidal dilatation and inflammatory cell infiltration, is prone to internal hemorrhage, hyperintensity on T2-weighted imaging, intense and persistent contrast enhancement, and no signal drop-off when comparing in- and out-of-phase images (a finding that indicates little change in the amount of intratumoral fat) [25]. Unfortunately, in the present case, MRI could not be performed because the patient felt claustrophobic within the machine, thus accurate diagnosis from imaging was difficult. To exclude the possibility of HCC, resection of the tumor was performed after obtaining informed 
consent from the patient.

In summary, although the risk of HCC development in patients with NAFLD has been noted recently [9]-[15], how HCC develops in NAFLD patients remains unclear. In the present case of IHCA, a $41 \times 38 \mathrm{~mm}$ SOL was detected in a liver showing NAFLD equal to steatohepatitis. A small number of reports of HCA with concomitant steatohepatitis have been described [26] [27]. In addition, some cases of HCC from metabolic syndrome are related to HCA [2]-[6]. In the present case, the patient was obese (BMI > 30), hypertensive, dyslipidemic, and had diabetes mellitus, suggesting features of metabolic syndrome. Furthermore, steatohepatitis was identified by pathologically. NAFLD is considered to be the liver component of metabolic syndrome [28]-[30]. This lesion with strong diffuse staining for GS suggesting $\beta$-catenin mutation against a background of metabolic disorder may indicate potential hepatocarcinogenesis from IHCA with concomitant steatohepatitis. From this perspective, many more cases of IHCA must be accumulated to allow phenotypic analysis of associations with malignant change.

This case was presented at the 49th Annual Meeting of the Liver Cancer Study Group of Japan, held in Tokyo from July 11-12, 2013.

\section{Conflict of Interest}

The authors declare that they have no conflicts of interest.

\section{References}

[1] Rooks, J.B., Ory, H.W., Ishak, K.G., et al. (1979) Epidemiology of Hepatocellular Adenoma. The Role of Oral Contraceptive Use. The Journal of the American Medical Association, 242, 644-648. http://dx.doi.org/10.1001/jama.1979.03300070040020

[2] Bioulac-Sage, P., Balabaud, C. and Wanless, I. (2010) Focal Nodular Hyperplasia and Hepatocellular Adenoma. In: Bosman, F., Ed., WHO Classification of Tumours of the Digestive System, 4th Edition, IRAC, Lyon, 198-204.

[3] Bioulac-Sage, P., Laumonier, H., Couchy, G., et al. (2009) Hepatocellular Adenoma Management and Phenotypic Classification: The Bordeaux Experience. Hepatology, 50, 481-489. http://dx.doi.org/10.1002/hep.22995

[4] Farges, O., Ferreira, N., Dokmak, S., et al. (2011) Changing Trends in Malignant Transformation of Hepatocellular Adenoma. Gut, 60, 85-89. http://dx.doi.org/10.1136/gut.2010.222109

[5] Sasaki, M., Yoneda, N., Kitamura, S., et al. (2011) Characterization of Hepatocellular Adenoma Based on the Phenotypic Classification: The Kanazawa Experience. Hepatology Research, 41, 982-988. http://dx.doi.org/10.1111/j.1872-034X.2011.00851.x

[6] Konishi, M., Ryu, M., Kinoshita, T., et al. (1995) A Case Report of Liver Cell Adenoma. Acta Hepatologica Japonica, 36, 223-229. http://dx.doi.org/10.2957/kanzo.36.223

[7] Lin, H., van den Esschert, J., Liu, C., et al. (2011) Systematic Review of Hepatocellular Adenoma in China and Other Regions. Journal of Gastroenterology and Hepatology, 26, 28-35. http://dx.doi.org/10.1111/j.1440-1746.2010.06502.x

[8] Paradis, V., Champault, A., Ronot, M., et al. (2007) Telangiectatic Adenoma: An Entity Associated with Increased Body Mass Index and Inflammation. Hepatology, 46, 140-146. http://dx.doi.org/10.1002/hep.21684

[9] Ascha, M.S., Hanouneh, I.A., Lopez, R., et al. (2010) The Incidence and Risk Factors of Hepatocellular Carcinoma in Patients with Nonalcoholic Steatohepatitis. Hepatology, 51, 1972-1978. http://dx.doi.org/10.1002/hep.23527

[10] Sanyal, A.J., Banas, C., Sargeant, C., et al. (2006) Similarities and Differences in Outcomes of Cirrhosis Due to Nonalcoholic Steatohepatitis and Hepatitis C. Hepatology, 43, 682-689. http://dx.doi.org/10.1002/hep.21103

[11] Hashimoto, E., Yatsuji, S., Tobari, M., et al. (2009) Hepatocellular Carcinoma in Patients with Non-Alcoholic Steatohepatitis. Journal of Gastroenterology, 44, 89-95. http://dx.doi.org/10.1007/s00535-008-2262-x

[12] Adams, L.A., Lymp, J.F., St Sauver, J., et al. (2005) The Natural History of Nonalcoholic Fatty Liver Disease: A Population-Based Cohort Study. Gastroenterology, 129, 113-121. http://dx.doi.org/10.1053/j.gastro.2005.04.014

[13] Ong, J.P., Pitts, A. and Younossi, Z.M. (2008) Increased Overall Mortality and Liver-Related Mortality in Nonalcoholic Fatty Liver Disease. Journal of Hepatology, 49, 608-612. http://dx.doi.org/10.1016/j.jhep.2008.06.018

[14] Rafiq, N., Bai, C., Fang, Y., et al. (2009) Long-Term Follow-Up of Patients with Nonalcoholic Fatty Liver. Clinical Gastroenterology and Hepatology, 7, 234-238. http://dx.doi.org/10.1016/j.cgh.2008.11.005

[15] Kawamura, Y., Arase, Y., Ikeda, K., et al. (2012) Large-Scale Long-Term Follow-Up Study of Japanese Patients with Non-Alcoholic Fatty Liver Disease for the Onset of Hepatocellular Carcinoma. The American Journal of Gastroenterology, 107, 253-261. http://dx.doi.org/10.1038/ajg.2011.327 
[16] Van Aalten, S.M., Verheij, J., Terkivatan, T., et al. (2011) Validation of a Liver Adenoma Classification System in a Tertiary Referral Centre: Implications for Clinical Practice. Journal of Hepatology, 55, 120-125. http://dx.doi.org/10.1016/j.jhep.2010.10.030

[17] Zucman-Rossi, J., Jeannot, E., Nhieu, J.T., et al. (2006) Genotype-Phenotype Correlation in Hepatocellular Adenoma: New Classification and Relationship with HCC. Hepatology, 43, 515-524. http://dx.doi.org/10.1002/hep.21068

[18] Bioulac-Sage, P., Rebouissou, S., Thomas, C., et al. (2007) Hepatocellular Adenoma Subtype Classification Using Molecular Markers and Immunohistochemistry. Hepatology, 46, 740-748. http://dx.doi.org/10.1002/hep.21743

[19] de La Coste, A., Romagnolo, B., Billuart, P., et al. (1998) Somatic Mutations of the Beta-Catenin Gene Are Frequent in Mouse and Human Hepatocellular Carcinomas. Proceedings of the National Academy of Sciences of the United States of America, 95, 8847-8851. http://dx.doi.org/10.1073/pnas.95.15.8847

[20] Miyoshi, Y., Iwao, K., Nagasawa, Y., et al. (1998) Activation of the Beta-Catenin Gene in Primary Hepatocellular Carcinomas by Somatic Alterations Involving Exon 3. Cancer Research, 95, 2524-2527.

[21] Nhieu, J.T., Renard, C.A., Wei, Y., et al. (1999) Nuclear Accumulation of Mutated Beta-Catenin in Hepatocellular Carcinoma Is Associated with Increased Cell Proliferation. The American Journal of Pathology, 155, 703-710. http://dx.doi.org/10.1016/S0002-9440(10)65168-1

[22] Fulcher, A.S. and Sterling, R.K. (2002) Hepatic Neoplasms: Computed Tomography and Magnetic Resonance Features. Journal of Clinical Gastroenterol, 34, 463-471. http://dx.doi.org/10.1097/00004836-200204000-00019

[23] Hussain, S.M., van den Bos, I.C., Dwarkasing, R.S., et al. (2006) Hepatocellular Adenoma: Findings at State-of-theArt Magnetic Resonance Imaging, Ultrasound, Computed Tomography and Pathologic Analysis. European Radiology, 16, 1873-1886. http://dx.doi.org/10.1007/s00330-006-0292-4

[24] Ronot, M., Bahrami, S., Calderaro, J., et al. (2011) Hepatocellular Adenomas: Accuracy of Magnetic Resonance Imaging and Liver Biopsy in Subtype Classification. Hepatology, 53, 1182-1191. http://dx.doi.org/10.1002/hep.24147

[25] Katabathina, V.S., Menias, C.O., Shanbhogue A.K.P., et al. (2011) Genetics and Imaging of Hepatocellular Adenomas: 2011 Update. Radiographics, 31, 1529-1543.

[26] Watkins, J., Balabaud, C., Bioulac-Sage, P., et al. (2009) Hepatocellular Adenoma in Advanced-Stage Fatty Liver Disease. European Journal of Gastroenterology and Hepatology, 21, 932-936. http://dx.doi.org/10.1097/MEG.0b013e328311a67c

[27] Brunt, E.M., Wolverson, M.K. and Di Bisceglie, A.M. (2007) Benign Hepatocellular Tumors (Adenomatosis) in Nonalcoholic Steatohepatitis: A Case Report. Seminars in Liver Disease, 25, 230-236. http://dx.doi.org/10.1055/s-2005-871202

[28] Vega, G.I., Chandalia, M., Szczepaniak, L.S., et al. (2007) Metabolic Correlates of Nonalcoholic Fatty Liver in Women and Men. Hepatology, 46, 716-722. http://dx.doi.org/10.1002/hep.21727

[29] van der Poorten, D., Milner, K.L., Hui, J., et al. (2008) Visceral Fat a Key Mediator of Steatohepatitis in Metabolic Liver Disease. Hepatology, 48, 449-457. http://dx.doi.org/10.1002/hep.22350

[30] Fan, J.G., Li, F., Cai, X.B., et al. (2007) Effects of Nonalcoholic Fatty Liver Disease on the Development of Metabolic Disorders. Journal of Gastroenterology and Hepatology, 22, 1086-1091.

http://dx.doi.org/10.1111/j.1440-1746.2006.04781.x 